\title{
Experimental and analytical study on high-speed fracture phenomena and mechanism of glass
}

\author{
H. Sakamoto ${ }^{1}$, S. Kawabe ${ }^{1}$, Y. Ohbuchi ${ }^{1}$ \& S. Itoh ${ }^{2}$ \\ ${ }^{I}$ Department of Mechanical Engineering and Materials Science, \\ Kumamoto University, Japan \\ ${ }^{2}$ Okinawa National College of Technology, Japan
}

\begin{abstract}
The new high-speed crushing technique of glass bottles was proposed for recycling. The proposed system uses the underwater shock-wave by explosive energy. This method is excellent compared with the conventional mechanical method in the crushing time, crushing efficiency, collection ratio of glass "cullet" and using simple crushing apparatus etc. In this study, using commercial beer bottle, the behaviors of underwater shock-wave by explosive energy and the high-speed fracture phenomena of glass bottle were clarified by the experiment and analytical method.

Keywords: glass-cullet, underwater shockwave, explosive enemy, high-speed fracture, recycle.
\end{abstract}

\section{Introduction}

Glass bottles are widely used as containers of drinks, food and medicine due to their characteristics for sealing up, transparency and storage stability. Many of these glass bottles after use are reused as returnable bottles or recycled as the raw material of glass container which is called 'cullet' that are crushed to small fragments $[1,2]$. The authors paid attention to this raw material recycling process of generating "cullet". In the conventional cullet generation method, a mechanical crushing one is used [3]. In order to recycle them by using this method, these bottles need to be washed inside before melting. As the bottles' shapes vary greatly, this washing of the bottles' inside takes a lot of time and it is 
difficult to do this operation automatically. In addition, the noise of this process is large and some of glass fragments also disperse.

Then, the new cullet generation technique which used the underwater shockwave by explosive energy was proposed for overcoming these problems. This proposed technique has a simultaneous crushing and pre-washing function. In this report, the behavior of underwater shock-wave by explosive energy and the high-speed fracture phenomena of glass bottles were clarified by the experiment and analytical method for the recycling of glass containers.

\section{Experiment}

\subsection{Experimental method}

The schemes of experimental apparatus are shown in Fig.1. The experiment was done in an explosion-proof steel container, which had been filled with water. The glass bottles were given underwater shockwave by two kinds of explosive, string type (1) and ball type (2) shown in Fig.1. The glass fragments called 'cullet' were all collected and the weight of each fragment size was measured after the explosive experiment.

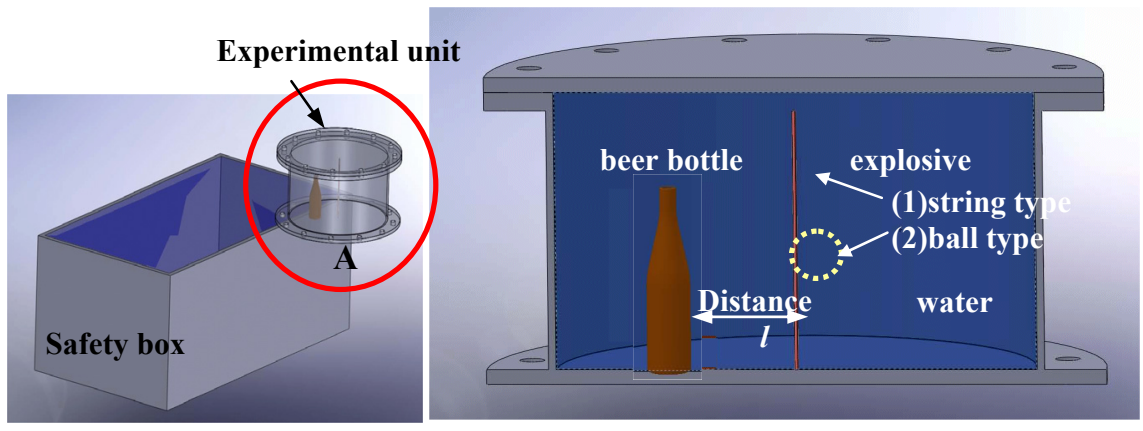

(a) Explosion proof container

(b) Detail A

Figure 1: Scheme of experimental apparatus.

\subsection{Specimens and experimental conditions}

We used a commercial beer bottle ( $500 \mathrm{cc}, \mathrm{H}=250 \mathrm{~mm}, \mathrm{D}=72 \mathrm{~mm}, 430 \mathrm{~g}$ ) as the experimental glass bottle (shown in fig. 2). The inside of the bottle was charged with air and the bottle and explosive were set (as shown in fig.1).

The distance $l$ shown in fig. 1 of the explosive and the bottle in order to examine the effect on the fragment grain sizes have been changed. The six distances from explosive to bottle were determined as follows: $l=100 \mathrm{~mm}$, $50 \mathrm{~mm}, 40 \mathrm{~mm}, 30 \mathrm{~mm}, 20 \mathrm{~mm}$ and $10 \mathrm{~mm}$. 


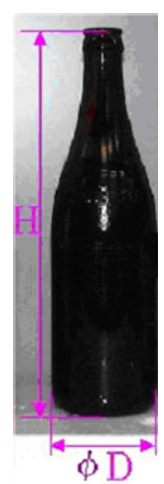

Figure 2: $\quad$ Specimen (beer bottle).

The PETN(explosive rate: $6308 \mathrm{~m} / \mathrm{s}$ ) as explosive and the electric detonator as ignition were used and explosive shape.

\subsection{Observation of high-speed fracture process}

In order to visualize the behavior of underwater shock-wave and the bottle fracture process, a high-speed photograph system was used, which consisted of a high-speed camera (IMECOM 468) and two Xenon flashlights (H1/20/50 type). The optical observation system is shown in fig. 3

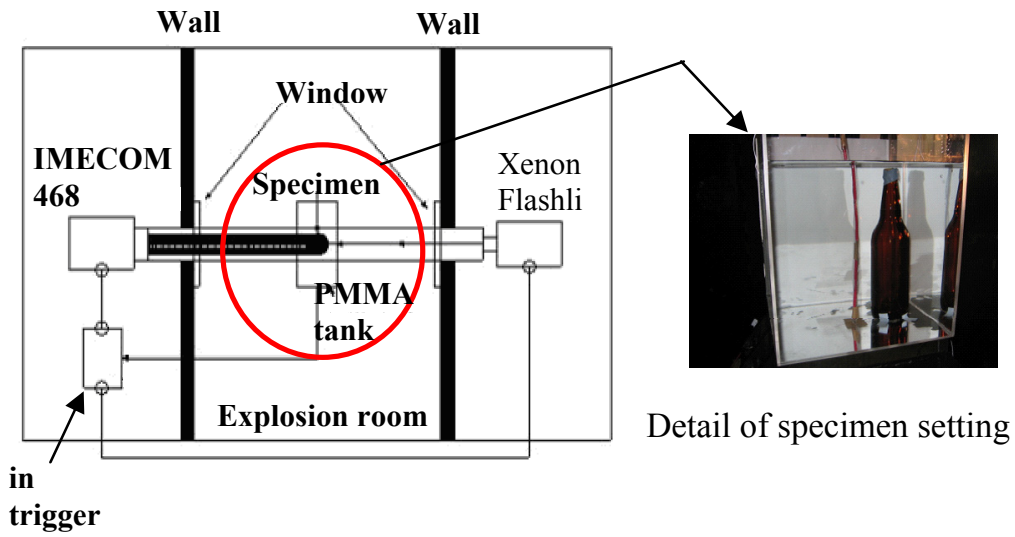

Figure 3: Optical observation system. 


\section{Experimental results}

\subsection{Cullet distribution}

The fragments of glass bottle were collected and these 'cullets' were classified by three kinds of sieves $(4.75 \mathrm{~mm}, 2 \mathrm{~mm}, 1 \mathrm{~mm})$ and each weight was measured.

The weight ratio in the case of string type explosive is shown in fig.4.

From fig. 4 , it is found that the weight of $1 \mathrm{~mm}$ or less cullet size decreases as the distance increases and the weight ratio of $1 \mathrm{~mm}$ or less grain size increases as the distance decreases. Here, it is interesting that the weight ratio of the $1 \sim 2 \mathrm{~mm}$ cullet size is almost constant regardless of the distance $l$.

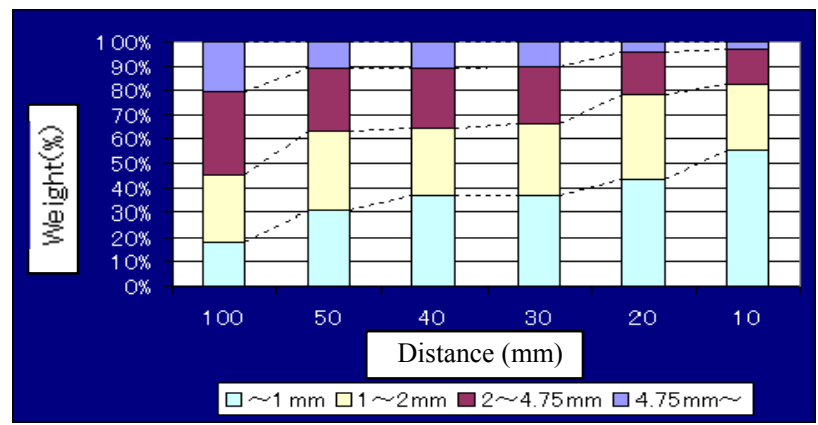

Figure 4: Effect of distance between the explosive and the bottle on cullet size (String type explosive case).

\subsection{Fracture process observation}

The glass bottle was charged the underwater shock wave by explosive shown in Fig. 1. Here, the behaviors of underwater shock-wave by explosive energy and the high-speed fracture phenomena of glass bottle were observed by a high-speed photography method. The photograph was taken using an Image Converter Highspeed camera (IMECOM468) and Xenon flashlight (H1/20/50type) as lighting.

Figure 5 shows the behaviors of shock wave in the case of string type explosive. Figure 6 shows the one in the case of ball type explosive. The appearance of the shock wave propagation can be clearly observed from these figures.

From figs. 5 and 6, the appearances of shock -wave propagation in the case of string type and ball type were illustrated in fig.7 (a), (b), respectively.

Next, we show some examples of fracture framing photographs. Figure 8 shows the fracture process in the case of string type explosive. In order to clarify the appearance of the deformation and fracture process, white paints are painted on the bottle surface. After the shock-wave propagated, the generation of the explosion-gas was seen from the photographs. 


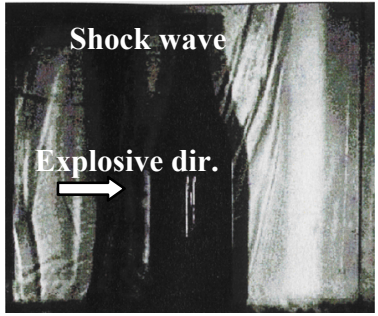

(a) $80 \mu \mathrm{s}$

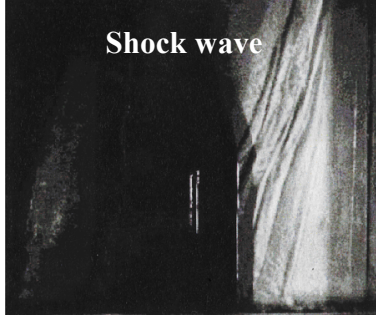

(b) $100 \mu \mathrm{s}$

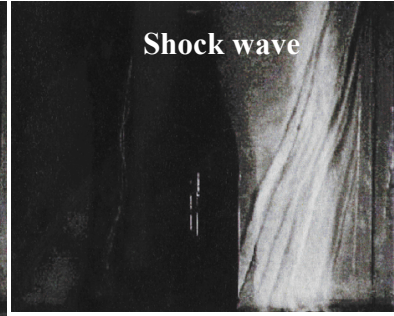

(c) $120 \mu \mathrm{s}$

Figure 5: $\quad$ Shock-wave propagation (string type explosive).

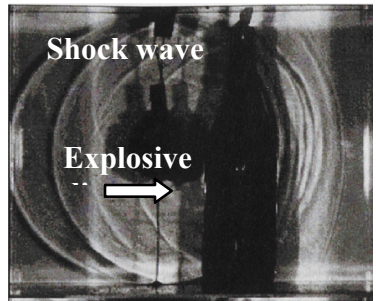

(a) $80 \mu \mathrm{s}$

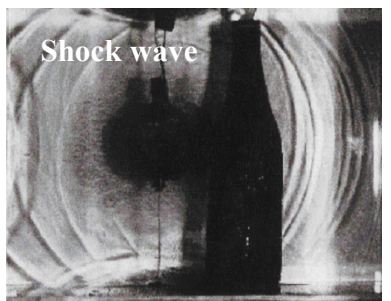

(b) $100 \mu \mathrm{s}$

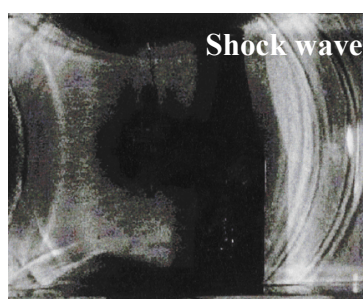

(c) $120 \mu \mathrm{s}$

Figure 6: $\quad$ Shock-wave propagation (ball type explosive).

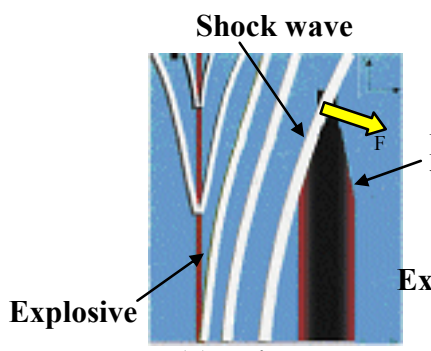

(a) string type

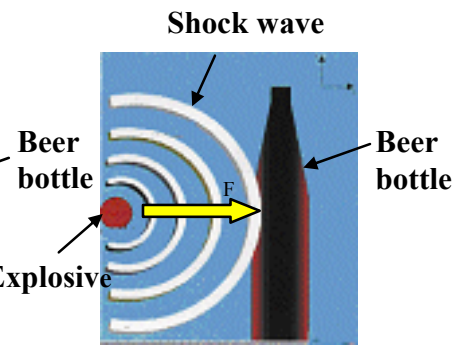

(b) ball type

Figure 7: Illustration of shock-wave propagation. 


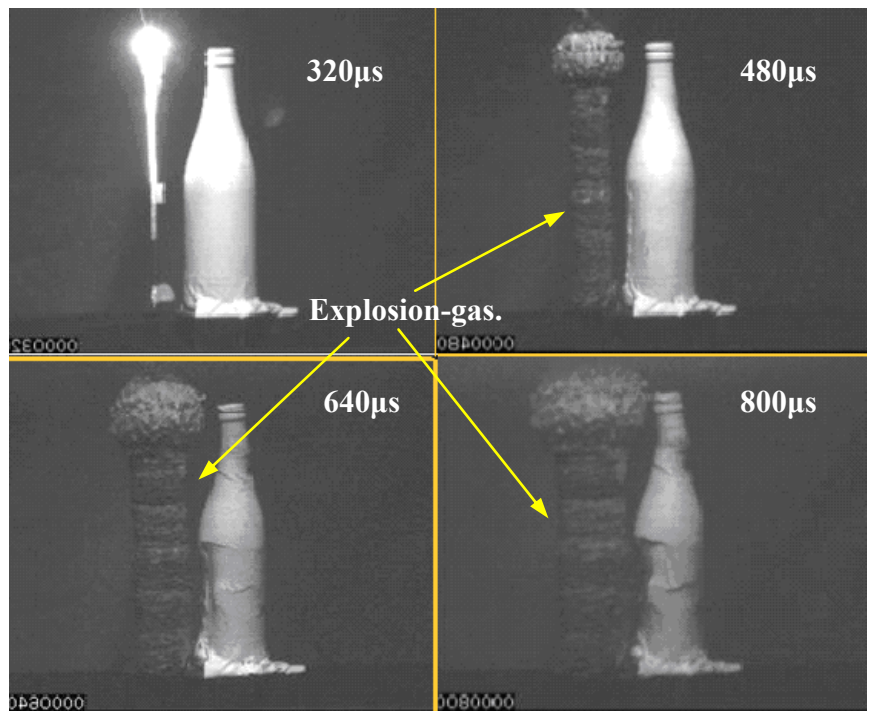

Figure 8: The behaviors by underwater shock wave.

\section{FEM simulation}

The fracture behaviors of bottles submitted to underwater shock-wave was simulated using the FEM analysis (FEM code: LS-DYNA) [4].

In this simulation, 2-D model (shock-wave propagation analysis) and 3Dmodel (shock-wave propagation analysis and fracture analysis) were employed. 2-D and 3-D analysis models are shown in fig.9 (a) and (b), respectively.
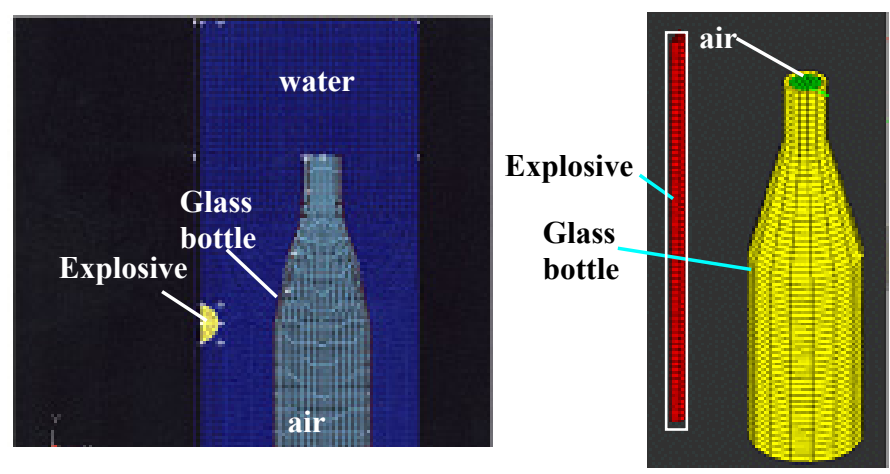

(a) 2-D analysis model

(b) 3-D analysis model

Figure 9: The behaviors by underwater shock wave. 
The 2-D simulation result is shown in fig.10. The behavior of shock-wave propagation agrees well with experimental results shown in fig.5.

Next, 3-D simulation results are shown. Figure 11 shows the fracture process of glass bottle by string type explosive. These simulation results are corresponding to the observation ones obtained by high-speed photography method.

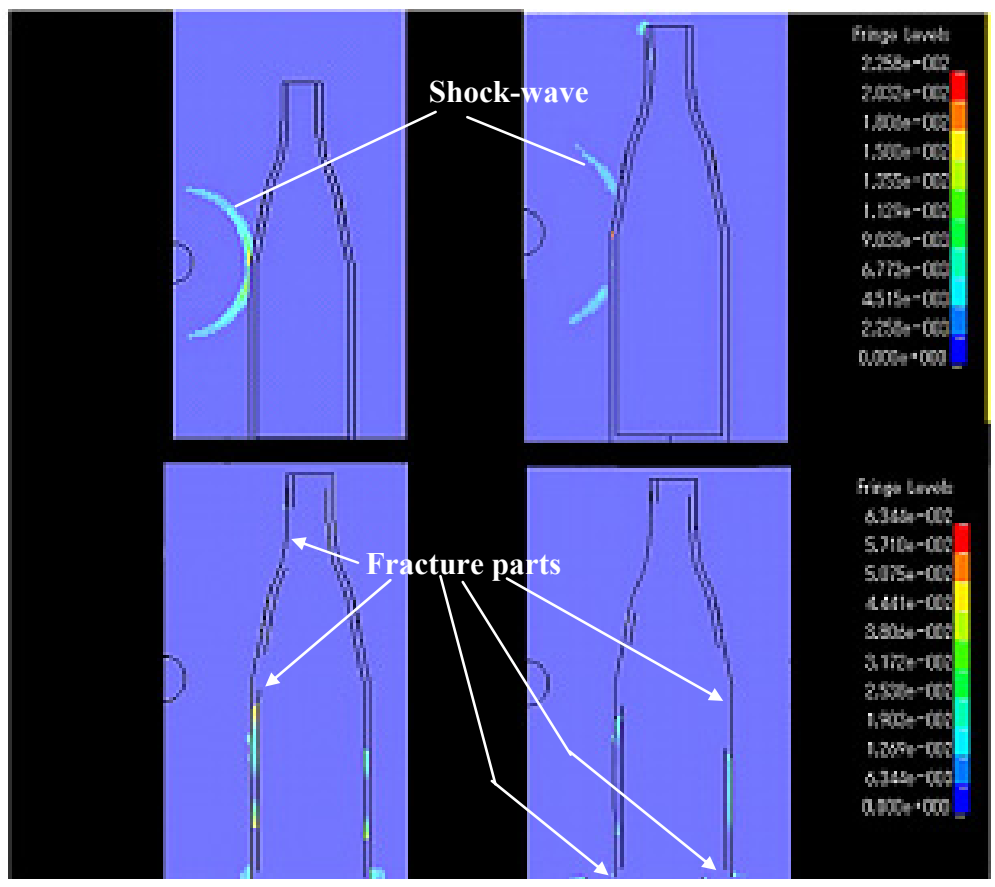

Figure 10: The behaviors of underwater shock wave by 2-D FEM simulation.

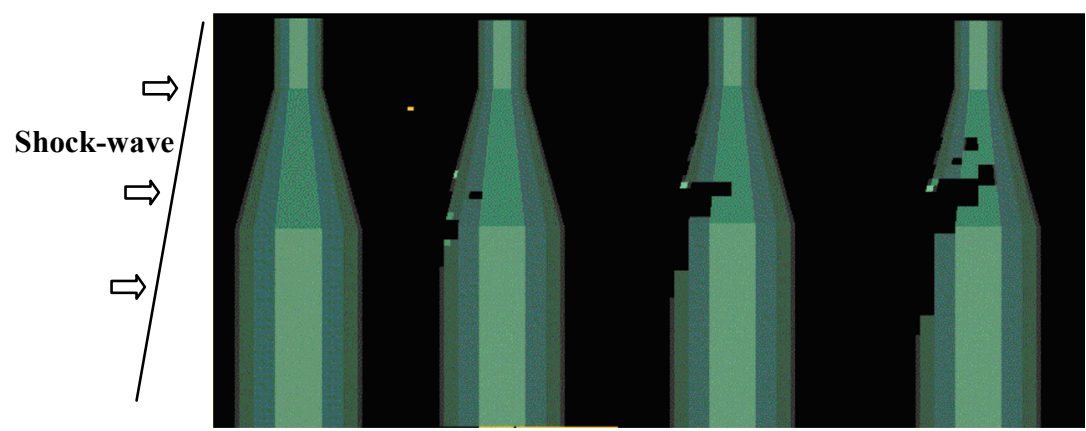

Figure 11: The fracture process by underwater shock wave (3-D FEM simulation in the case of string type explosive). 


\section{Conclusions}

The relation between strength of underwater shockwave and fracture "cullet" grain size were discussed and the behaviors of shock-wave and fracture process by shock-wave were discussed. The results obtained are summarized as follows:

1) The weight ratio of the small 'cullet' grain sizes increases as the distance decrease and the weight ratio of the $1 \sim 2 \mathrm{~mm}$ cullet size is almost constant regardless of the distance $l$.

2) The behaviors of shock-wave generated by explosive energy and the highspeed fracture process were clarified by using a high-speed photograph method and FEM simulation.

\section{References}

[1] Sakka, S., The dictionary of glass, Asakura Press Ltd., 1998.

[2] Kobayashi, A.S., Experimental Techniques in Fracture Mechnics, Society for Experimental Stress Analysis ,1973.

[3] Sakamoto, H., et al, WIT transactions on Modelling and Simulation, Vol.41, pp.497-503,2005.

[4] V.P.W. Shim, S. Tanimura, C.T. Lim, Impact Response of Materials \& Structure, Oxford University Press, 1999. 